\title{
An Experimental Mathematics Course for Middle and High School Mathematics Teachers
}

\author{
Abhijit Nagchaudhuri ${ }^{1}$ / Daniel M. Seaton ${ }^{2}$ \\ University of Maryland Eastern Shore
}

\begin{abstract}
Too often mathematics content instruction for classroom teachers tends to be abstract and devoid of practical applications. However, simple devices and computer software, especially Computer Aided Engineering (CAE) software can help integrate physics and engineering applications into a mathematics class without loss of focus. In this paper we report our experiences in developing and delivering an experimental mathematics course to secondary in-service mathematics teachers where software and devices reinforce important concepts. The course structure balanced rigor with utility in secondary instructional environments.
\end{abstract}

\section{Introduction}

Recent state and federal accountability requirements have renewed interest in student achievement in mathematics ${ }^{[1]}$. In addition, many states monitor local school productivity against predetermined benchmarks of effectiveness and have attached well-publicized rewards and sanctions including school accreditation classifications and ranking systems $^{[2,3]}$. State sanctions based on assessment scores can affect graduation, student diplomas, school accreditation, school funding, teacher rewards and promotion, paperwork requirements, regulations, work expectations, improvement plans, and even real estate values. However, modest and initial gains in the results of high-stakes accountability assessments may accompany trends toward instruction that is more for procedural rather than for conceptual knowledge and increasingly traditional rather than reform-oriented ${ }^{[4]}$.

Pressure on local districts to recruit and retain qualified teachers comes at the same time as critical and well-documented shortages of mathematics teachers. Traditional mathematics teacher education programs that require mathematics content courses generally taught in mathematics departments supplemented by professional education courses have failed to prepare teachers in sufficient quality and quantity to meet current demands ${ }^{[5]}$. Recent graduates enter the mathematics teaching profession already in desperate need of intensive professional development ${ }^{[6]}$. Moreover, state and district efforts to recruit and retain teachers too often fail to benefit high-poverty, high-minority, and low achieving schools where inexperienced and out-of-field teachers are more likely [7]. Consequently, efforts toward professional development of the current teacher workforce hold the greatest promise for improved achievement.

Fortunately, NCLB facilitates partnerships between K-12 districts and higher education institutions to provide teachers with professional development opportunities including

\footnotetext{
${ }^{1}$ Associate Professor of Engineering and Aviation Sciences

2 Assistant Professor of Mathematics and Computer Sciences

Proceedings of the 2005 American Society for Engineering Education Annual Conference \& Exposition Copyright (C) 2005, American Society for Engineering Education
} 
those that improve their content knowledge, focus on research-based practices, and align with state standards ${ }^{[8]}$. The core knowledge required to teach mathematics for deep understanding is fundamentally different from what many teachers, have had opportunities to learn ${ }^{[6]}$. In addition to content knowledge and knowledge of pedagogy, the knowledge base for effective teaching of mathematics includes pedagogically functional knowledge. Mathematics content development experiences should encourage teachers to connect concepts across a variety of mathematical content areas, connect the mathematics they learn with the mathematics they will teach, and reflect on teaching while engaged in learning ${ }^{[5]}$. Teachers tend to teach mathematics in ways that are consistent with how they learned mathematics ${ }^{[9-11]}$. Consequently, teachers need opportunities to reconstruct their understanding of mathematics content and expand their views of what understanding mathematics involves through curriculum and instructional approaches that are similar to those which they will later use in their classrooms ${ }^{[6]}$. Substantial improvements in teachers' conceptual understanding and dramatic shifts toward reform-oriented instructional approaches have resulted from opportunities to learn mathematics content in these kinds of pedagogy implicit settings ${ }^{[6,12]}$. Content instruction in pedagogy implicit settings significantly increases mathematics teacher self-efficacy and outcomes-expectancy beliefs ${ }^{[13]}$.

While considerable evidence supports integrated approaches to teaching mathematics, science, and technology in schools ${ }^{[14-18]}$, less has been written about training teachers for integrated instruction. Still, teacher development programs that integrate content are beginning to emerge. Hamm ${ }^{[19]}$ proposed methods courses to improve scientific literacy by integrating science, mathematics, and technology in instruction that combines subject matter and pedagogical knowledge. Evans ${ }^{[20]}$ and Thomas, Cooper, and Ponticell ${ }^{[21]}$ describe staff development programs for in-service mathematics teachers that use inquiry-based, science and mathematics classroom instruction. Instruction that integrates science and mathematics process skills is common, but consistent integration of content material requires changes to current teacher development practices ${ }^{[22]}$. Increases in teachers' mathematics and science self-efficacy beliefs have resulted from completing integrated mathematics and science methods courses ${ }^{[23]}$. Integrated investigations provide teachers with opportunities to engage in the creative aspects of mathematics discovery and exploration. Appropriate problems should be immediately attractive, require data to be generated and analyzed using technology, appeal to students from junior high school to graduate school, involve fundamental mathematical concepts, have satisfying solutions, and suggest several other problems for further investigation ${ }^{[24}$. Not incidentally, Venville, Wallace, Rennie, and Malon ${ }^{[25]}$ recognized the importance of integrating content from science, mathematics, and technology learning areas, but noted the absence of recent research on how students learn science and mathematics concepts in integrated settings.

\section{Objectives and Outcomes}

The experimental course offered at the University of Maryland Eastern Shore (UMES) in the summer of 2004 was developed to provide professional development for local secondary teachers. The course involves mathematical analysis of simple physical systems using computer aided engineering (CAE) tools (Working Model) and 
spreadsheet (EXCEL). The course introduces fundamentals of engineering mechanics and design, hand held GPS, and robotics with hands-on exposure to Lego-Mindstorm's Robotic Invention System. The course activities provided hands-on, project-based, experiences to enhance and integrate understanding of physics, mathematics, and engineering fundamentals and in doing so, encouraged participating in-service teachers to re-examine their own teaching.

Course participants were expected to:

- Reinforce understanding of essential mathematics content;

- Improve appreciation of Newton's Laws of Motion and applications in engineering mechanics.

- Develop skills and insights to use computer aided engineering tools and spreadsheet programs to analyze and design simple physical systems.

- Enhance ability to develop hands-on, experiential learning projects that promote integrated learning of mathematics, science and engineering fundamentals suitable for use in middle and high schools.

\section{Highlights}

The course was designed to reinforce concepts related to Newton's Laws of Motion and fundamentals of Statics and Dynamics components of the Engineering Mechanics sequence. The Working Model 2D ${ }^{[26]}$ was used to simulate simple spring mass system in statical equilibrium as well as simple kinematic devices set in motion using a virtual motor (the popular four bar mechanism). Teacher participants also worked in teams to build simple devices such as a weighing machine based on the design principle of moment balance along the same lines as a Bismar or a Steelyard scale (popularly renamed "Moment Machine") ${ }^{[27]}$. These devices provided a realistic framework to introduce statical equilibrium conditions, solutions to simultaneous systems of equations, and Sine Law, Cosine law, and other trigonometry concepts. Other mathematics content experiences including iterative solutions of nonlinear equations, basic differentiation and its' relation to slope of a curve, and Newton Raphson method for solving nonlinear equations lend themselves to spreadsheet applications.

Particle equilibrium problems in "Statics" involve solving simultaneous equations for 3dimensional problems arising out of force equilibrium in three Cartesian directions. Initially, teacher participants were introduced to simple problems that resulted in linear equations in 2 and 3 unknowns that could be solved easily with requisite knowledge of trigonometry and geometry. Subsequent experiences involved solving the following problem involving spring, rope and an applied force as shown in Figure 1a and $1 \mathrm{~b}$ below $^{[28]}$.

The problem seeks a solution for angle $\theta$ assuming the rope and spring are of length $\mathrm{x}=$ $2 \mathrm{ft}$. and a force of $\mathrm{F}=10 \mathrm{lb}$. is applied at the joint of rope and spring as illustrated in Figure 1a. Since rope is not stretched, its' length does not change. The spring length changes ( $\mathrm{s} \mathrm{ft}$.) in accordance with the spring constant $(\mathrm{k}=15 \mathrm{lb} / \mathrm{ft}$.). From the free body diagram of point $\mathrm{A}$ in Figure $1 \mathrm{~b}$ and using appropriate trigonometry and algebra in the resulting triangle $\mathrm{ABC}$ in Figure 1a, the following equations are formulated:

Proceedings of the 2005 American Society for Engineering Education Annual Conference \& Exposition Copyright (C) 2005, American Society for Engineering Education 


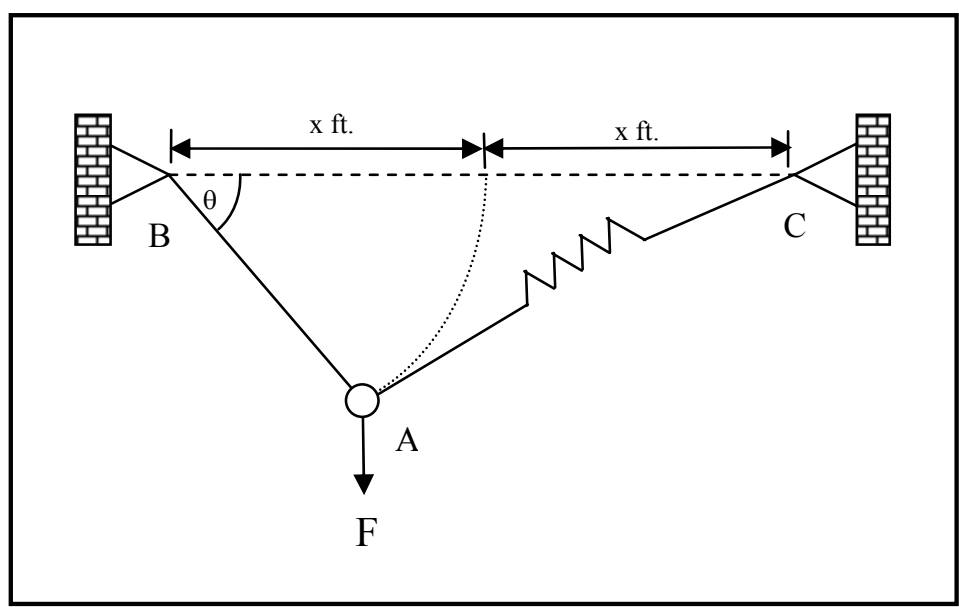

Figure 1a: 2-D Statics Problem (non-linear)

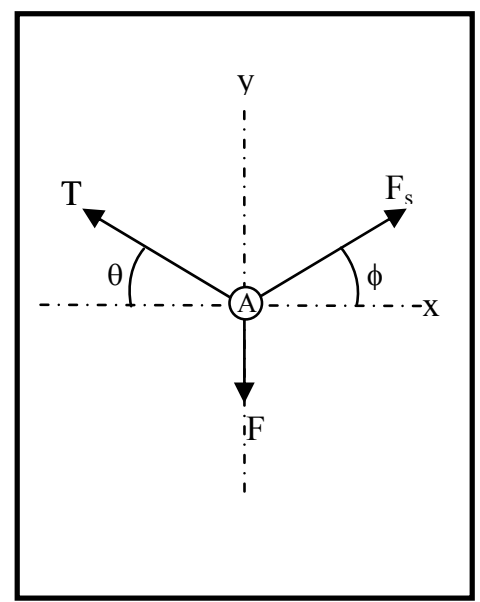

Figure $1 \mathrm{~b}$ : F.B.D. of pt. A

Spring force $\mathrm{F}_{\mathrm{s}}$ (from triangle $\mathrm{ABC}$ ): $\mathrm{F}_{\mathrm{s}}=\mathrm{ks}=2 \mathrm{k}(\sqrt{5-4 \cos \theta}-1)$

Angle $\phi$ in terms of angle $\theta$ (from triangle $A B C$ ):

$$
\varphi=\arctan \left(\frac{2 \sin \theta}{4-2 \cos \theta}\right)=\arctan \left(\frac{\sin \theta}{2-\cos \theta}\right)
$$

Tension in rope $(\mathrm{T})$ from Equation statical equilibrium in $\mathrm{x}$-direction:

$$
\sum \mathrm{F}_{\mathrm{x}}=0 \Rightarrow \mathrm{F}_{\mathrm{s}} \cos \varphi-\mathrm{T} \cos \theta=0
$$

Equation (1) can be manipulated easily to obtain $\mathrm{T}=\mathrm{F}_{\mathrm{s}}\left(\frac{\cos \varphi}{\cos \theta}\right)$

Statical equilibrium in y direction: $\sum \mathrm{F}_{\mathrm{y}}=0 \Rightarrow \mathrm{T} \sin \theta+\mathrm{F}_{\mathrm{s}} \sin \varphi-10=0$

With appropriate substitution Equation (2) can be expressed as a nonlinear equation of a single variable $\theta$.

This provided a framework for discussing solutions of nonlinear equations using Newton Raphson. Values of $\theta$ from 0 to 90 degrees were entered into the first spreadsheet column followed by $\mathrm{F}_{\mathrm{s}}$ (spring force), $\phi$ (phi), $\mathrm{T}$ (tension in rope) and finally Equation 2 in the last column. The transition from positive to negative values in the last column indicates the location of roots. The interval could be resolved more finely to obtain a solution for $\theta$, the spring force, and the tension in the rope. The first iteration in search for solutions used $\theta$ values ranging from 0 to 90 degrees at 10 degree intervals. The zero crossing in the last column (Equation 2) lies between 30 and 40 degrees indicating the solution lies between 30 degrees and 40 degrees. TABLE-1 displays the an EXCEL spreadsheet in which rows were inserted first at intervals of 2 degrees between 30 degrees and 40 degrees and then at 0.5 degrees between 34 and 36 degrees (since the zero crossing was between 34 and 36 degrees). Clearly, 35 degrees is a reasonably accurate solution since the expression in the final column is very close to zero at 35 degrees. The spring force $\left(\mathrm{F}_{\mathrm{s}}\right)$ and rope tension $(\mathrm{T})$ at 35 degrees is $9.383 \mathrm{lbs}$. and $10.303 \mathrm{lbs}$. respectively. 
Teachers participating were quick to point out that iterative approaches would allow still finer estimates and that the method is similar to the bisection method of solving nonlinear equations.

\begin{tabular}{|c|c|c|c|c|c|}
\hline Th & $\theta=(\mathrm{pi} / 180)$ th & $\begin{array}{c}F s= \\
k^{*} 2(\operatorname{sqrt}(5- \\
4 \cos \theta)-1)\end{array}$ & $\phi=\arctan (2 \sin \theta / 4-2 \cos \theta)$ & $\mathrm{T}=\mathrm{Fs}(\cos \phi / \cos \theta)$ & $T \sin \theta+F \sin \phi-10$ \\
\hline 0 & 0 & 0 & 0 & 0 & -10 \\
\hline 10 & 0.174527778 & 0.898039928 & 0.169405345 & 0.898839248 & -9.692516607 \\
\hline 20 & 0.349055556 & 3.422954531 & 0.312022446 & 3.466733401 & -7.763548424 \\
\hline 30 & 0.523583333 & 7.179036441 & 0.415275878 & 7.584992352 & -3.311277743 \\
\hline 32 & 0.558488889 & 8.039393146 & 0.431146934 & 8.612258259 & -2.076551423 \\
\hline 34 & 0.593394444 & 8.928517922 & 0.445519869 & 9.718354794 & -0.718165983 \\
\hline 34.5 & 0.602120833 & 9.154942351 & 0.448885559 & 10.00802236 & -0.358645209 \\
\hline 35 & 0.610847222 & 9.382933363 & 0.452162068 & 10.30319714 & 0.009029076 \\
\hline 35.5 & 0.619573611 & 9.612446698 & 0.455350341 & 10.6040151 & 0.384957986 \\
\hline 36 & 0.6283 & 9.843438723 & 0.458451334 & 10.91061885 & 0.769248431 \\
\hline 38 & 0.663205556 & 10.78134297 & 0.47000195 & 12.19798974 & 2.392385458 \\
\hline 40 & 0.698111111 & 11.73957786 & 0.48023466 & 13.59123974 & 4.15960208 \\
\hline 50 & 0.872638889 & 16.75354135 & 0.513847456 & 22.69729249 & 15.62165212 \\
\hline 60 & 1.047166667 & 21.96059769 & 0.523598775 & 38.03483637 & 33.91884601 \\
\hline 70 & 1.221694444 & 27.17172022 & 0.515630071 & 69.10871754 & 68.33801616 \\
\hline 80 & 1.396222222 & 32.24725349 & 0.494536393 & 163.4168927 & 166.238363 \\
\hline 90 & 1.57075 & 37.08079624 & 0.463656874 & 715912.2244 & 715918.807 \\
\hline
\end{tabular}

TABLE - 1 Subsequent Iterations to Obtain the Solution

Working Model 2D/Interactive Physics allowed participants to simulate realistic situations arising in engineering mechanics problems (Statics as well as Dynamics). The screenshot shown in Figure 2 displays an instance of the animated solution of the problem after the spring-mass-rope system stabilized. The force of $10 \mathrm{lbs}$. was realized by $10 \mathrm{lb}$ weight hung from the joint of the $2 \mathrm{ft}$ rope and $2 \mathrm{ft}$. spring simulated in the software. The rope tension and spring force can also be measured and displayed in the software. Clearly the results confirm the EXCEL solution. The spring force and rope tension as displayed in the screenshot are $9.377 \mathrm{lbs}$ and $10.296 \mathrm{lbs}$. The screenshot also shows that the length of the spring stretches to $31.502 \mathrm{in}$. but the length of the rope remains fixed at $24 \mathrm{in}$.

The "Moment Machine" construction and design, a popular exercise in one of the ongoing middle school outreach programs at UMES ${ }^{[29]}$, was appropriately included in this course. While the emphasis with the middle school students has generally been the demonstration of the moment balance principle and its' application in designing the "moment machine", analysis using EXCEL and the open-ended nature of the design problem with multiple solutions were highlighted for our teacher participants. Based on the principle of levers and moment balance, this unequal arm balance is similar to a Steelyard or Bismar scale. The object to be weighed $\left(\mathrm{W}_{\mathrm{u}}\right)$ and the counterweight $\left(\mathrm{W}_{\mathrm{c}}\right)$ are located on the shorter side to the left of the pivot and the adjustable or sliding weight $\left(\mathrm{W}_{\mathrm{a}}\right)$ is located to the right of the pivot on the longer side - the arm with appropriate calibration marks. 


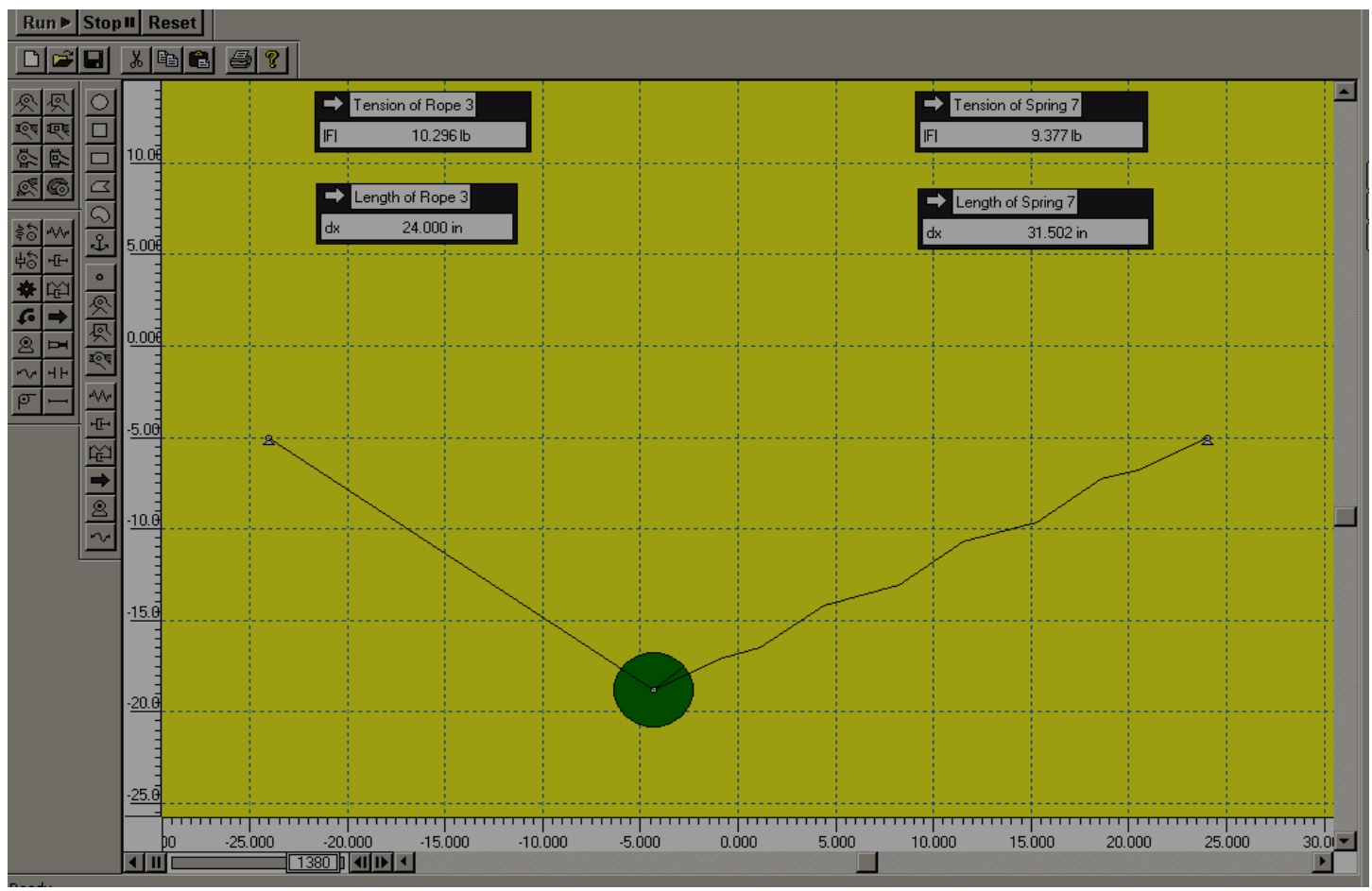

FIGURE 2: Working Model 2D /Interactive Physics solution

Assuming that $\mathrm{L}_{\mathrm{c}}, \mathrm{L}_{\mathrm{u}}, \mathrm{L}_{\mathrm{a}}$ and $\mathrm{L}_{\mathrm{b}}$ are the distances of the counterweight $\left(\mathrm{W}_{\mathrm{c}}\right)$, unknown weight to be measured $\left(\mathrm{W}_{\mathrm{u}}\right)$, sliding weight $\left(\mathrm{W}_{\mathrm{a}}\right)$ and the center of the balance beam (center of gravity from which its' weight $\mathrm{W}_{\mathrm{b}}$ acts) from the pivot, the moment balance equation for the unequal arm balance ( see Figure 3 ) can be written as:

$$
\mathrm{W}_{\mathrm{c}} \mathrm{L}_{\mathrm{c}}+\mathrm{W}_{\mathrm{u}} \mathrm{L}_{\mathrm{u}}-\mathrm{W}_{\mathrm{a}} \mathrm{L}_{\mathrm{a}}-\mathrm{W}_{\mathrm{b}} \mathrm{L}_{\mathrm{b}}=0
$$

There are several variables in Equation 3, and several solutions exist. The participants' first task was to get an intuitive feel for the "Moment Machine" by designing an arrangement that would weigh items from 0 to 500 grams. The locations for the counterweight, unknown weight and pivot were chosen with due regard to the length of the beam and other considerations relevant to the design problem. Reasonable choices were "eyed" and subsequently measured. Pivot location at $23.4 \mathrm{~cm}$ from the left hand corner and $76.4 \mathrm{~cm}$ from the right hand corner $\left(100 \mathrm{~cm}\right.$ beam length) and $\mathrm{L}_{\mathrm{c}}=17.9 \mathrm{~cm}$ and $\mathrm{L}_{\mathrm{u}}=6.5 \mathrm{~cm}$ were chosen. These choices resulted from splitting the beam into unequal arms by locating the pivot at roughly $1 / 3^{\text {rd }}$ the length of the beam, locating the counterweight close to the left hand corner, and locating the container for the unknown weight close to the pivot but without touching the vertical rod in the frame as shown in Figure 3.

First the " 0 " is located and marked on the beam by sliding the adjustable weight close to the pivot, without any weight in the cup, thereafter the adjustable weight is slid to the extreme right of the beam with a 500 gram weight in the cup. Calibration marks are made at $25 \mathrm{~g}$ intervals with appropriate calibration weights in the cup and adjustments in the sliding weight location. In all cases balance is achieved when the beam is horizontal. 
Some trial and error of the counterweight and adjustable weight magnitudes were necessary to achieve the desired results. Subsequent to this exercise participants were challenged to design an arrangement to weigh 0 to 800 grams with the same apparatus. EXCEL spreadsheet was utilized to choose an appropriate arrangement for the variables in Equation 3 so as to allow a feasible solution.

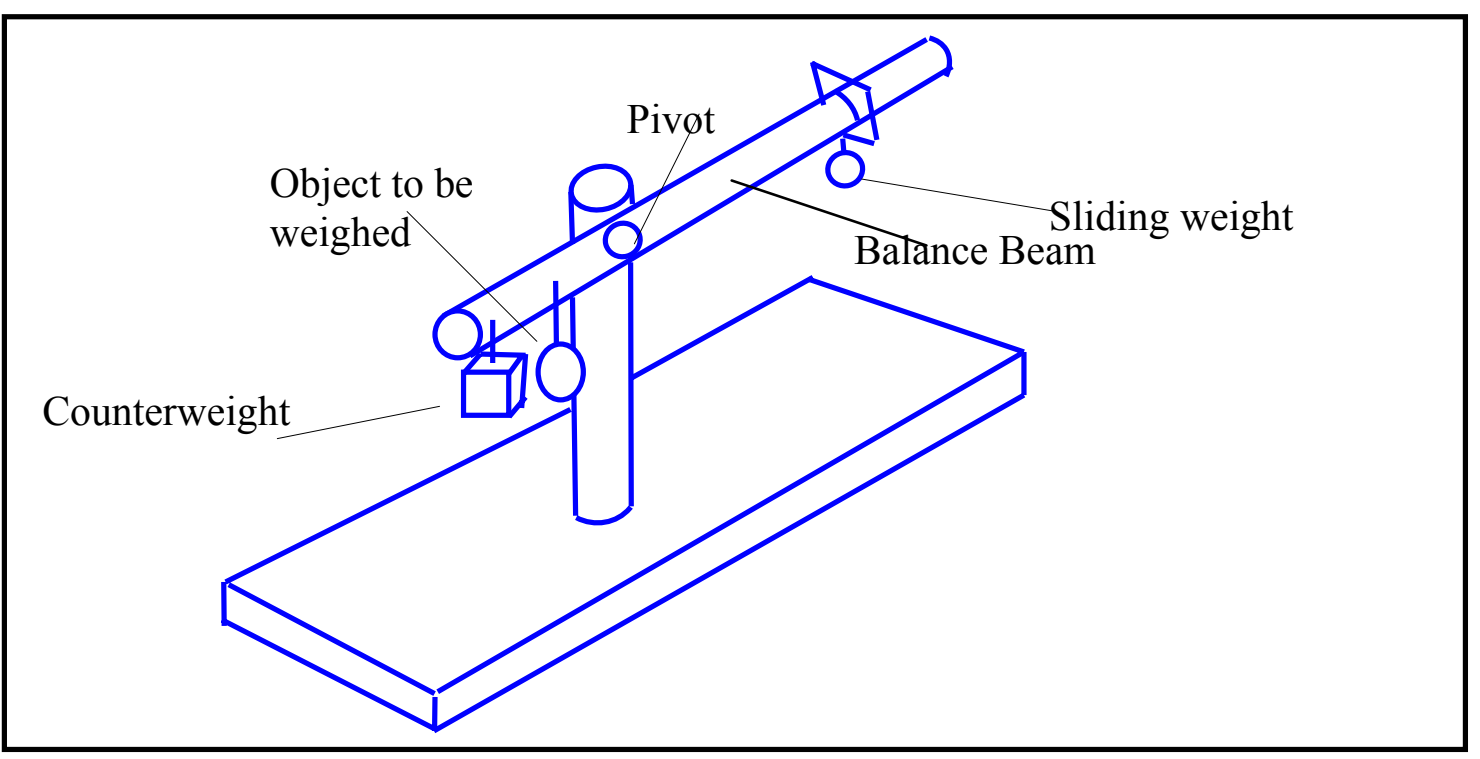

FIGURE 3: Schematic of the Moment Machine

The solution proceeded by the decision to keep the locations for the weights and pivots the same as before, thereby reducing the number of variables. An electronic scale was utilized to weigh the plastic cup (container for $\mathrm{W}_{\mathrm{u}}=9.44 \mathrm{~g}$ ), counterweight $(65.69 \mathrm{~g})$, adjustable weight $(38.39 \mathrm{~g})$, and the beam $(52.15 \mathrm{~g})$. The $2 \mathrm{~g}$ locknuts were utilized to adjust the counterweight and the adjustable weight and for all arrangements $L_{a}$. The distance of the adjustable siding weight to the right of the pivot was calculated using Equation 3 in the EXCEL spreadsheet. A portion of the EXCEL spreadsheet developed by one of the teams is shown in Table 3.

While all solution pairs shown are mathematically feasible, only the solution pairs highlighted satisfy the constraints in the problem. The weight of the beam acts at its' center $50 \mathrm{~cm}$ from the corners and $26.6 \mathrm{~cm}$ to the right of the pivot. The weights of $9.44 \mathrm{~g}$ and $809.44 \mathrm{~g}$ correspond to no weight in the cup and $800 \mathrm{~g}$ in the cup respectively. The solutions are for $2 \mathrm{~g}$ increments in counterweight and adjustable weight. With preliminary choices in locations, the length of the beam to the right of the pivot is $76.4 \mathrm{~cm}$. This limits the distance of the adjustable weight from $5-7 \mathrm{~cm}$ to the right of the pivot for " 0 " and roughly $76.4-3 / 5=73.4 / 71.4 \mathrm{~cm}$ to the right of the pivot for the $800 \mathrm{~g}$ unknown. These choices when physically applied to the beam balance yielded satisfactory results; calibration marks were made at $25 \mathrm{~g}$ intervals with known calibration weights. This phase of the course was concluded by introducing the teachers to the West Point Bridge Design Software. The bridge design concepts complemented previous discussions related to 
"Statics". Finally, the participant teams prepared lesson plans and materials for use in K12 classes using the concepts introduced thus far.

\begin{tabular}{|r|c|r|r|r|r|r|r|}
\hline \multicolumn{1}{|c|}{$\mathrm{Wc}$} & $\mathrm{Lc}$ & \multicolumn{1}{c|}{$\mathrm{Wu}$} & $\mathrm{Lu}$ & $\mathrm{Wb}$ & $\mathrm{Lb}$ & $\mathrm{Wa}$ & $\mathrm{La}=(\mathrm{WcLc}+\mathrm{WuLu}-\mathrm{WbLb}) / \mathrm{Wa}$ \\
\hline 93.69 & 17.9 & 9.44 & 6.5 & 52.15 & 26.6 & 66.39 & 5.290269619 \\
\hline 93.69 & 17.9 & 809.44 & 6.5 & 52.15 & 26.6 & 66.39 & 83.61531857 \\
\hline 95.69 & 17.9 & 9.44 & 6.5 & 52.15 & 26.6 & 68.39 & 5.659029098 \\
\hline 95.69 & 17.9 & 809.44 & 6.5 & 52.15 & 26.6 & 68.39 & 81.69353707 \\
\hline 97.69 & 17.9 & 9.44 & 6.5 & 52.15 & 26.6 & 70.39 & 6.006833357 \\
\hline 97.69 & 17.9 & 809.44 & 6.5 & 52.15 & 26.6 & 70.39 & 79.88096321 \\
\hline 99.69 & 17.9 & 9.44 & 6.5 & 52.15 & 26.6 & 72.39 & 6.335419257 \\
\hline 99.69 & 17.9 & 809.44 & 6.5 & 52.15 & 26.6 & 72.39 & 78.16854538 \\
\hline 101.69 & 17.9 & 9.44 & 6.5 & 52.15 & 26.6 & 74.39 & 6.646336873 \\
\hline 101.69 & 17.9 & 809.44 & 6.5 & 52.15 & 26.6 & 74.39 & 76.5482054 \\
\hline 103.69 & 17.9 & 9.44 & 6.5 & 52.15 & 26.6 & 76.39 & 6.940973949 \\
\hline 103.69 & 17.9 & 809.44 & 6.5 & 52.15 & 26.6 & 76.39 & 75.01271109 \\
\hline 105.69 & 17.9 & 9.44 & 6.5 & 52.15 & 26.6 & 78.39 & 7.220576604 \\
\hline 105.69 & 17.9 & 809.44 & 6.5 & 52.15 & 26.6 & 78.39 & 73.55556831 \\
\hline 107.69 & 17.9 & 9.44 & 6.5 & 52.15 & 26.6 & 80.39 & 7.486266949 \\
\hline 107.69 & 17.9 & 809.44 & 6.5 & 52.15 & 26.6 & 80.39 & 72.17092922 \\
\hline 109.69 & 17.9 & 9.44 & 6.5 & 52.15 & 26.6 & 82.39 & 7.739058138 \\
\hline 109.69 & 17.9 & 809.44 & 6.5 & 52.15 & 26.6 & 82.39 & 70.85351378 \\
\hline 111.69 & 17.9 & 9.44 & 6.5 & 52.15 & 26.6 & 84.39 & 7.979867283 \\
\hline 111.69 & 17.9 & 809.44 & 6.5 & 52.15 & 26.6 & 84.39 & 69.59854248 \\
\hline
\end{tabular}

Table 2 - Moment Machine Analysis

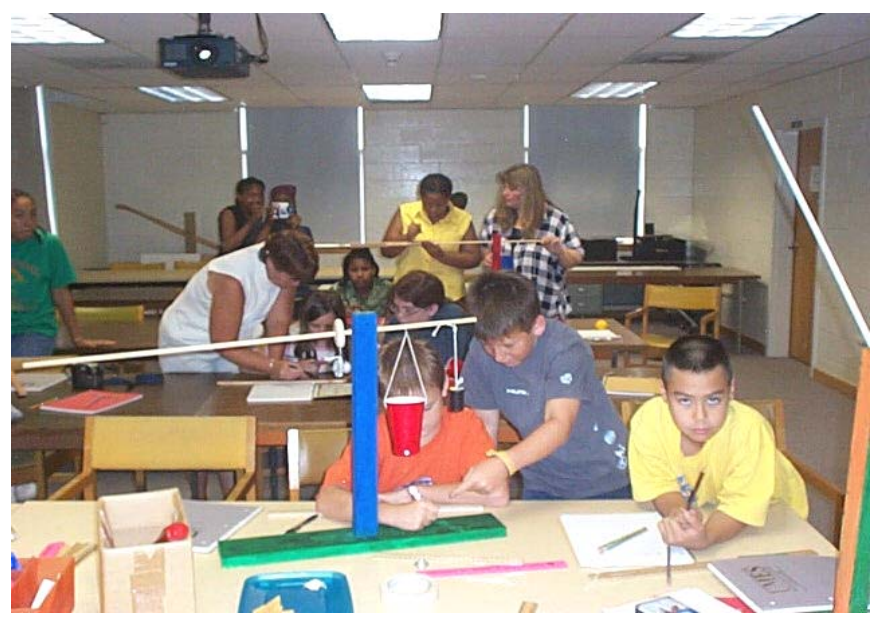

Figure 3: Middle School Students working on "Moment Machine"

Discussion pertaining to "Dynamics" followed the "Statics" portion of the course. Four bar linkages provided the background for the discussion. Following Norton ${ }^{[30]}$, teacher participants worked in teams to design on paper a four bar linkage system that would have a rocking angle of 45 degree. The four bar linkage consists of a ground or fixed link, a crank which is supposed to rotate at a constant rpm using a motor or engine, a

Proceedings of the 2005 American Society for Engineering Education Annual Conference \& Exposition Copyright (C) 2005, American Society for Engineering Education 
connecting rod, and follower which is supposed to provide the desired motion (typically, a back and forth rocking motion of varying rocking angle according to design specification). Many devices including those found in amusement parks, exercise machines, and camera shutter mechanisms are based on an appropriately designed four bar linkage. It was left to participants as a matter of discovery that for the crank of the four-bar mechanism to rotate 360 degrees it is necessary to satisfy Grashof condition $(\mathrm{S}+\mathrm{L}<\mathrm{P}+\mathrm{Q}$; the sum of the shortest and longest link must be less than the sum of the other two links). Teachers could easily design the lengths of each of the links on paper using appropriate geometrical construction for desired rocking angle of 45 degree. A few iterations were necessary to ensure that the lengths obtained do indeed satisfy the Grashof condition. Pieces of cardboard and thumbtacks were used to put together a working mechanism. Also the Working Model 2D/Interactive Physics software was used to construct and animate a four bar mechanism producing the appropriate rocking angle. A screenshot of a simulated four bar mechanism while it is undergoing motion in the Working Model 2D/Interactive Physics environment is shown in Figure 4a. The light blue links are those corresponding to the various positions of the links as the crank undergoes 360 degree motion (tracked every 16 frames in the software). The dark blue links show the initial configuration of the fourbar linkage. The various links and their corresponding names are indicated in the Figures $4 \mathrm{a}$ and $4 \mathrm{~b}$. The angle $\mu$ between the connecting rod and the follower is important from the kinetic consideration as it determines the efficacy of force transmission from the connecting rod and the follower ( $\mathrm{F}_{3}$ to 4 in Figure $4 \mathrm{~b}$ ) and is termed the " transmission angle" of the four bar linkage. The component $\mathrm{F}_{3}$ to $4 \sin (\mu)$ is responsible for the motion of the follower. Therefore, a good four bar linkage design tries to keep the angle $\mu$ as high as possible (at least 45 degrees) throughout the rotation of the crank.

After completing the first phase of the four bar mechanism design purely from kinematic considerations, two more solutions involving different link lengths that would satisfied the Grashof condition as well as the rocking angle of 45 degree were sought and obtained. Participants, then, used EXCEL and fundamental trigonometry to analyze the three different solutions and identify the best solution using kinetic considerations.

Using the Law of Cosines (see Figure 4b):

$$
\begin{aligned}
& Z^{2}=r_{1}{ }^{2}+r_{2}{ }^{2}-2 r_{1} r_{2} \cos (\theta)=r_{3}{ }^{2}+r_{4}{ }^{2}-2 r_{3} r_{4} \cos (\mu) \\
& \cos (\mu)=\left(r_{1}{ }^{2}+r_{2}{ }^{2}-2 r_{1} r_{2} \cos (\theta)-r_{3}{ }^{2}-r_{4}{ }^{2}\right) /-2 r_{3} r_{4}
\end{aligned}
$$

From Equation 4, it is possible to solve for all values of transmission angle $(\mu)$ as the crank rotates by substituting values of $(\theta)$ at suitable intervals from 0 to 360 degree. It was convenient to use EXCEL for the purpose. Using known values of the link lengths for the three kinematically feasible solutions obtained before, it was possible to compare the resulting transmission angle to pick the best solution from kinetic consideration. This phase of the course also concluded with the teachers developing a lesson materials based on the four bar mechanism design exercise for use in their classrooms. 


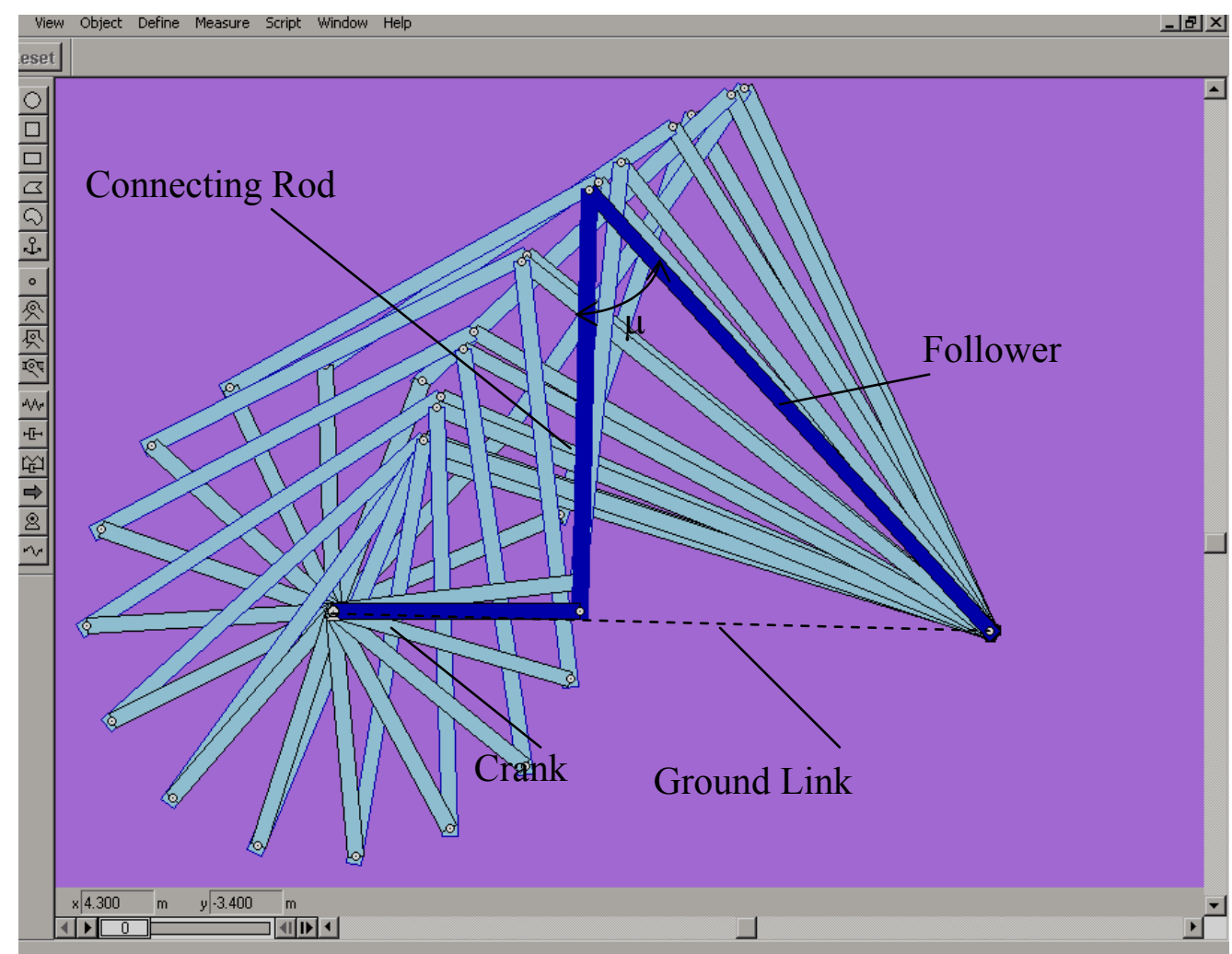

Figure 4a: Four bar linkage animation in Working Model 2D

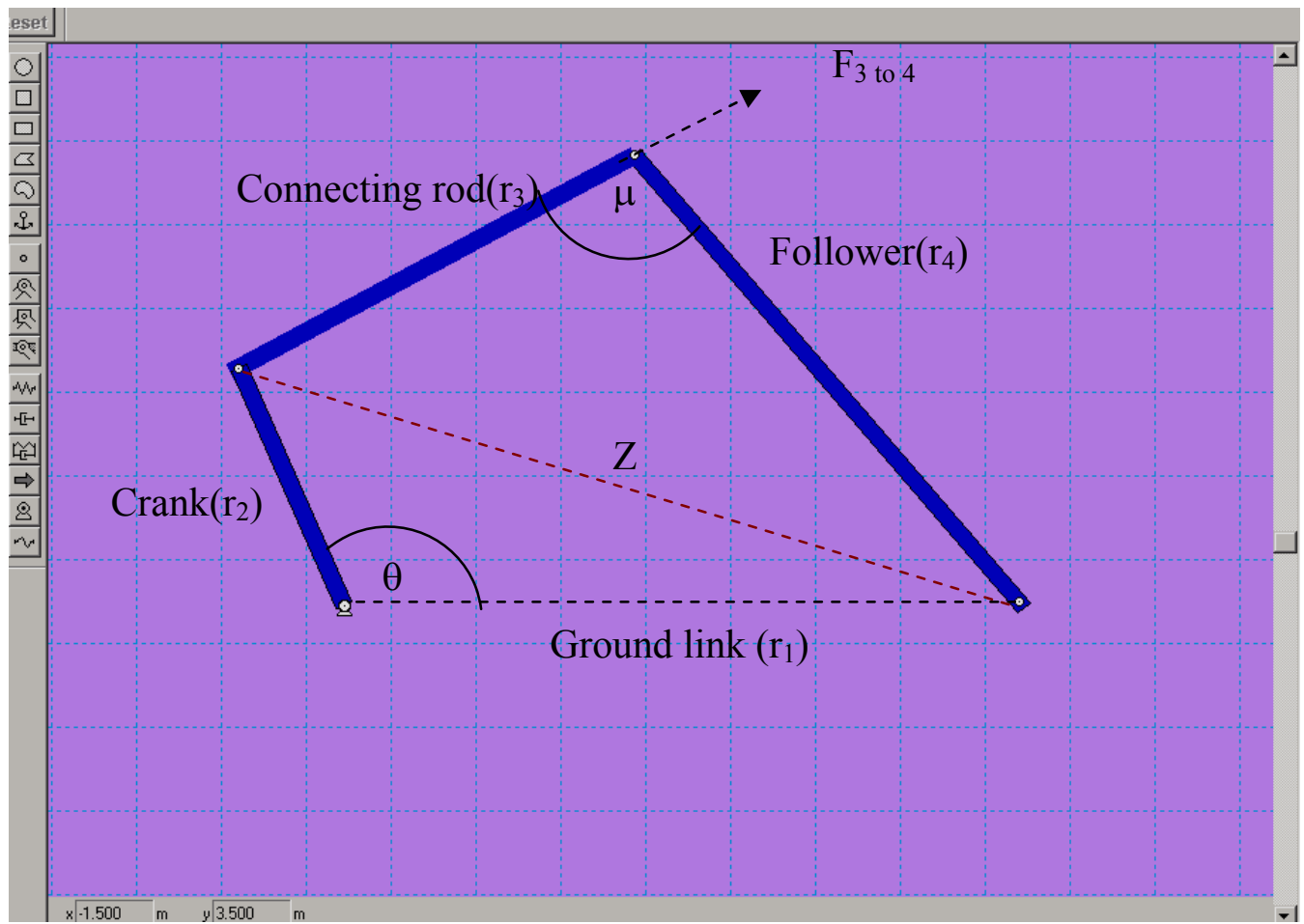

Figure 4 b. Four bar Linkage - Transmission Angle

Proceedings of the 2005 American Society for Engineering Education Annual Conference \& Exposition Copyright (C) 2005, American Society for Engineering Education 
A course component focusing on vectors, vector dot products, and vector cross products was included. Fundamentals of latitude and longitude, the spheroidal and ellipsoidal earth models, as well as Geographical Positioning Systems (GPS) were reviewed. If the earth is assumed to be a sphere of radius $r$ and if $A$ and $B$ are two points on the surface of the earth with latitude and longitude of $\left(a_{1}, a_{2}\right)$ and $\left(b_{1}, b_{2}\right)$, then the position vectors $\mathbf{O A}$ and OB from the center of the earth $\mathrm{O}$ to points $\mathrm{A}$ and $\mathrm{B}$ on the surface can be represented as:

$$
\begin{aligned}
& \mathbf{O A}=r \cos \left(a_{1}\right) \cos \left(a_{2}\right) \mathbf{i}+r \cos \left(a_{1}\right) \sin \left(a_{2}\right) \mathbf{j}+r \sin \left(a_{1}\right) \mathbf{k} \\
& \mathbf{O B}=r \cos \left(b_{1}\right) \cos \left(b_{2}\right) \mathbf{i}+r \cos \left(b_{1}\right) \sin \left(b_{2}\right) \mathbf{j}+r \sin \left(b_{1}\right) \mathbf{k}
\end{aligned}
$$

where $\mathbf{i}, \mathbf{j}$, and $\mathbf{k}$ are unit vectors in the three-dimensional Cartesian coordinate directions. The magnitude of vectors $\mathbf{O A}$ and $\mathbf{O B}$ is radius $\mathrm{r}$ of the earth. By definition the dot product $\mathbf{O A} . \mathbf{O B}=|\mathbf{O A} \| \mathbf{O B}| \cos (\theta)$ can be expanded and simplified:

$$
\begin{gathered}
r^{2} \cos (\theta)=r^{2}\left(\cos \left(a_{1}\right) \cos \left(a_{2}\right) \cos \left(b_{1}\right) \cos \left(b_{2}\right)+\cos \left(a_{1}\right) \sin \left(a_{2}\right) \cos \left(b_{1}\right) \sin \left(b_{2}\right)+\sin \left(a_{1}\right) \sin \left(b_{1}\right)\right. \\
\theta=\arccos \left(\sin \left(a_{1}\right) \sin \left(b_{1}\right)+\cos \left(a_{1}\right) \cos \left(b_{1}\right) \cos \left(a_{2}-b_{2}\right)\right)
\end{gathered}
$$

An approximate distance can be easily obtained between points $\mathrm{A}$ and $\mathrm{B}$ by using the expression $\mathrm{S}=\mathrm{r} \theta$, where $\mathrm{S}$ is the arc joining points $\mathrm{A}$ and $\mathrm{B}$ along a great circle (the circumference of the circular plane passing through $\mathrm{A}$ and $\mathrm{B}$ and the center of the earth) subtending the angle $\theta$ at the center of the earth. A rough approximation for $r$ is $6371 \mathrm{~km}$. When the angle $\theta$ is expressed in degrees instead of radians, the distance may be obtained by multiplying $\theta$ by $111 \mathrm{~km}\left(111^{\sim} 6371 * 180 / \pi\right.$, the distance on the surface of the earth for each degree latitude.) Following Carlson and Clay ${ }^{[31]}$, the more accurate ellipsoidal earth model and the geodeticlgeocentric latitudes and longitudes were reviewed. The teachers also used hand-held GPS technology to find latitudes and longitudes of points placed at known distances and verified the distances using EXCEL.

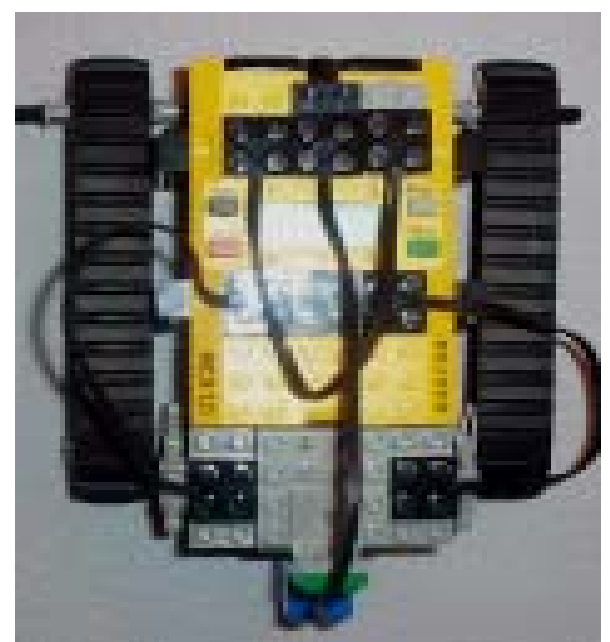

Figure 5: Tankbot (LEGO)

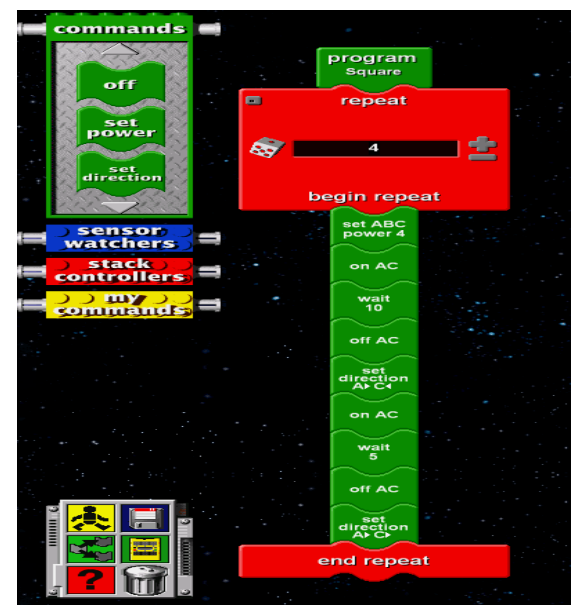

Figure 6: RCX-Code

With local private support, Nagchaudhuri ${ }^{[32]}$ has helped establish a state of the art robotics and control facility at UMES for teaching, research, and K-12 outreach 
programs. This course introduced the teachers to the construction and programming of robotic devices made with the Lego Mindstorm Robotics Invention System kits. The teachers used the tankbot [Figure 5] and were challenged to create programs to make a square trajectory with $3 \mathrm{ft}$. long edges traversed in a total of 60 seconds. While programming the Lego robots is a valuable learning exercise in itself, the focus of this exercise centered on calculation of the correct speed, power and time settings necessary to covers the specified course. Figure 5 and Figure 6 show a tankbot and sample RCXcode to achieve the desired results. Consistent with other course activities, these experiences were followed with opportunities for teachers to develop lesson materials.

\section{Conclusion}

The K-12 teachers that participated in the course overwhelmingly expressed their satisfaction with the course. Appendix-I provides the detail breakdown of how the course was implemented with regard to time. The teachers developed excellent lesson plans based on the "Moment Machine" and "Four Bar Mechanism" design projects for adaptation in K-12 environments. Developing lesson plans for the "Lat/Long/GPS" and "Lego robotics" project turned out to be more difficult for them. Most teachers who took the course have requested a similar course but entirely devoted to "robotics". The authors are offering such a course this summer. Discussions with the K-12 teachers revealed that cooperative effort is needed at the school level to coordinate Physics, Mathematics and Technology instruction to facilitate effective implementation of the lesson plans developed in this course. Feedback from the teachers after they implement these lesson plans in K-12 settings is crucial for appraising the efficacy of the course.

\section{Acknowledgment}

The authors would like to acknowledge the efforts of K-12 teachers and their flexibility to adapt to a new mode of learning. NASA-MASTAP Grant NRA 02 OEOP-02 provided the funding to develop and implement the course.

\section{Bibliography}

[1] Burger, Don (2002). Using standards-lead policy to align assessment and accountability systems. PREL Breifing Paper. Honolulu, HI: Pacific Resources for Education and Learning.(ERIC Document Reproduction Service No. ED473564)

[2] Gullatt, David E. (1999, August). Determining local school effectiveness through state accountability directives: A national and state perspective. Paper presented at the Annual Meeting of the National Council of Professors of Education Administration, Jackson Hole, WY.

[3] Claycomb, Carla \& Haynes, Mariana (2003). From sanctions to solutions: Meeting the needs of lowperforming schools. State Education Standard, 4(2), 4-9.

[4] Seaton, D., and Carr, D., (2004 March) The impact of participation in an ancilliary science and mathematic program(SEMAA) on engagement rates of middle school students in regular mathematics classrooms. Contributed presentation at the American Mathematics Society-Mathematics Education Reform Forum, Dubuque, IA.

[5] Graham K. J. \& Fennell F. (2001). Principles and standards for school mathematics and teacher education: Preparing and empowering teachers. School Science and Mathematics, 101(6), 319-327.

[6] Peck, d. M. \& Connell, M. L. (1991, April) Developing a pedagogically useful content knowledge in elementary mathematics. Paper presented at the Annual Meeting of the American Educational Research Association, Chicago, IL. 
[7] Langbort, Carol (1989, March). Making math leaders: the San Francisco mate leadership project. Paper presented at the Annual Meeting of the American Association of Colleges for Teacher Education, Anaheim, CA.

[8] Trahan, Christopher (2002). Implications of the no child left behind act of 2001 for teacher education. (ERIC Document Reproduction Service No. ED477723)

[9] Lloyd, Gwendolyn M. (2002). Mathematics teachers beliefs and experiences with innovative curriculum materials in G. Leder \& E. Pehkonen, (Eds.), Beliefs: A hidden variable in math3ematics education? (pp. 1-11). Netherlands: Kluwer Academic Publishers.

[10] Eisenhart, Margaret and others (1993). Conceptual knowledge falls through the cracks: Complexities of learning to teach mathematics for understanding. Journal forResearch in Mathematics Education, 24(1), 8-40.

[11] Foss, Donna H. \& Kleinsasser, Robert C. (1996). Preservice elementary teachers' view of pedagogical and mathematical content knowledge. Teaching and Teacher Education. 12(4), 429-42.

[12] Sneed, Lucy Carpenter (1998). Professional development for middle school mathematics teachers to help them respond to NCTM standards. Journal of Teacher Education, 49(4), 287-95.

[13] Seaton, Daniel M. (2003, November). Improving mathematics teaching self-efficacy beliefs through professional develop. Presentation at the Fall Meeting of the MD-DC-VA Section of the Mathematical Association of America, Baltimore, MD.

[14] Salyer, B, K \& Curran, C. (2002, March). What can I use tomorrow? Strategies for accessible math and science curriculum for diverse learners in rural schools. No child Left Behind: The vital role of rural schools. Annual National Conference Proceedings of the American Council on Rural Special Education, Reno, MV.

[15] Flourney, B. E., Cook-Bax, J. E., Harris, L. (2001). The science-mathematics connection: using technology in an interdisciplinary model. Science Teacher, 68(6), 63-66.

[16] Ramey, Linda K \& Tomlin, James (2001, March). Using the globe program to enhance classroom teaching. Paper presented at the Annual Meeting of the National Association for Research in Science Teaching, St. Louis, MO.

[17] Deed, D. G., Allen, C. S., Callen, B. W., \& Mark, D. (2000) A new paradigm in integrated math and science courses: finding common ground across disciplines. Journal of College Science Teaching, 30(3) 178-83.

[18] James, R. K. \& Lamb, C. E. (2000). Integrating science, mathematics, and technology in middle school technology-rich environment: a study of implementation and change. School Science and Mathematics. 100(1), 27

[19] Hamm, Mary (1992). Achieving scientific literacy through a curriculum connected with mathematics and technology. School Science and Mathematics, 92(1), 6-9.

[20] Evans, Norma (2001). Inquiry-based professional development: letting questions direct teachers' learning. Voyages in Mathematics and Science, (26).

[21] Thomas, J. A., Cooper, S. B., \& Ponticell, J. A. (2000). Doing math the science way: staff development for integrated teaching and learning. in D. J. McIntyre \& D. M. Byrd (Eds) Research on effective models for teacher education. Teacher education yearbook VIII. Reston, VA: Association of Teacher Educators.

[22] Roebuck, Kay I. \&Warden, Melissa A. (1998). Searching for the center on the mathematicsscience continuum. School Science and Mathematics, 98(6), 328-333.

[23] Scottile, James M., Carter, William, \& Murphy, Ruth Ann (2002, April). The influence of selfefficacy on school culture, science achievement, and math achievement among inservice teachers. Paper presented at the Annual Meeting of the American Educational Research Association, New Orleans, LA.

[24] Stevenson, F. W. (1992). Exploratory problems in mathematics. Reston, VA: National Council of Teachers of Mathematics, Inc.

[25] Venville, G. Wallace, J., Rennie, L., Malone, J. (2000). Bridging the boundaries of compartmentalized knowledge: student learning in an integrated environment. Research in Science and Technological Education, 18(1), 23-35.

[26] MSC. Software ( Knowledge Revolution) Working Model 2D User's Manual Version 5

[27] Dally, J.W. and Rocheleau, D.N., (1998) Introduction to Engineering Design, Book 3 ( Postal Scales), College House Enterprises, LLC, Knoxville, Tennessee.

[28] Hibbeler, R.C. ( 2003), Engineering Mechanics : Statics Prentice Hall Publishers

Proceedings of the 2005 American Society for Engineering Education Annual Conference \& Exposition Copyright (C) 2005, American Society for Engineering Education 
[29] Nagchaudhuri, A., and Singh, G.,(2003) Middle School students gets Introduced to Fundamentals of Engineering at the UMES-NOAA Summer Camp, Proceedings of the 2003 ASEE Annual Conference, Nashville, June 2003, CD ROM

[30] Norton, R.L., Design of Machinery- Introduction to the Synthesis and Analysis of Mechanisms and Machines, McGraw Hill Publishers

[31] Carlson, C.G. and Clay, D.E.,(2002) “ The Earth Model- Calculating Field Sizes and Distances Between Points Using GPS Coordinates" and other supplementary notes. Available Online @ URL http://www.precisionag.org/WestHills/Refrences/PPI/SSMG\%2011.pdf

[32] Nagchaudhuri, A., Srinivas, S., and Kundavaram, R.,(2004) Mechtraonics and Flexible Automation Efforts at the UMESMAL, Proceedings of Japan -USA Symposium on Flexible Automation, July 2004, Denver, Co.

\section{ABHIJIT NAGCHAUDHURI}

Abhijit Nagchaudhuri is currently an Associate Professor in the Department of Engineering and Aviation Sciences at University of Maryland Eastern Shore. Prior to joining UMES he worked in Turabo University in San Juan , PR as well as Duke University in Durham North Carolina as Assistant Professor and Research Assistant Professor, respectively. Dr. Nagchaudhuri is a member of ASME, SME and ASEE professional societies and is actively involved in teaching and research in the fields of engineering mechanics, robotics, systems and control and design of mechanical and mechatronic systems. Dr. Nagchaudhuri received his bachelors degree from Jadavpur University in Calcutta, India with a honors in Mechanical Engineering in 1983, thereafter, he worked in a multinational industry for 4 years before joining Tulane University as a graduate student in the fall of 1987. He received his M.S. degree from Tulane University in 1989 and Ph.D. degree from Duke University in 1992.

DANIEL M. SEATON

Daniel Seaton is currently an Assistant Professor in the Department of Mathematics and Computer Science at University of Maryland Eastern Shore. 


\section{Appendix -I}

\begin{tabular}{|c|c|c|}
\hline \multicolumn{3}{|c|}{ Course Schedule: } \\
\hline DATE & MORNING & AFTERNOON \\
\hline DAY -1, June 28, 2004 & $\begin{array}{l}\text { Review of mathematics fundamentals: } \\
\text {-Sine law, Cosine law, Pythagorus theorem, } \\
\text { Resolving forces and moments into orthogonal } \\
\text { components } \\
\text {-Solution of simultaneous equations } \\
\text {-Iterative solution of nonlinear equations using } \\
\text { bisection method. } \\
\text {-Introduction to EXCEL (bisection method) } \\
\text {-Basics of Geometry/Geometrical construction } \\
\text {-Hands On (Computer Lab) }\end{array}$ & $\begin{array}{l}\text { Slope and differentiation, Chain rule } \\
\text { Newton Raphson Method of solving nonlinear } \\
\text { equations. } \\
\text { Newton's Laws of Motion } \\
\text { Units - SI and FPS } \\
\text { Introduction to engineering mechanics } \\
\text { Statics, kinematics and kinetics. } \\
\text { Introduction to Projects } \\
\text { Simple machines, Moment Balance } \\
\text { Working Model and Project-1 (start) }\end{array}$ \\
\hline DAY-2, June 29, 2004 & $\begin{array}{l}\text { Complete Project-1, Resolution and Accuracy. } \\
\text { Analysis and Project report } \\
\text { Develop lesson plan for middle school } \\
\text { math/physics class. }\end{array}$ & $\begin{array}{l}\text { Solving basic statics problems using } \\
\text { simultaneous equations } \\
\text { Springs, spring constant and spring force, } \\
\text { Springs in series and Springs in parallel. } \\
\text { Spring problems in statics, nonlinear equations } \\
\text { and iterative solutions using EXCEL. } \\
\text { Solution using Working Model 2D } \\
\text { Introduction to Take Home Project } \\
\text { (Project 2) - Optional }\end{array}$ \\
\hline $\begin{array}{c}\text { DAY-3, June 30, } \\
2004\end{array}$ & $\begin{array}{l}\text { Mobility, Structures and Mechanisms. } \\
\text { Truss structures, bridges and West Point Bridge } \\
\text { Design ( Download Information). } \\
\text { Mechanisms, Inversion of Mechanisms, } \\
\text { Slider Crank and Fourbar Mechanism } \\
\text { Grashof Condition., Non Grashof fourbar } \\
\text { mechanisms and their use. } \\
\text { Start Project } 3 \text { - Phase I }\end{array}$ & $\begin{array}{l}\text { Complete Phase-I ( Project 3) } \\
\text { Animate using Working Model } \\
\text { Solve for maximum and minimum transmission } \\
\text { angle and other values of transmission angle for } \\
\text { different values of crank angle using EXCEL, } \\
\text { compare with physical device. } \\
\text { Criteria for efficient four bar mechanism- } \\
\text { Introduction to Project } 3 \text { (Phase - II) }\end{array}$ \\
\hline DAY- 4, July 1, 2004 & $\begin{array}{l}\text { Optimize fourbar mechanism for efficiency } \\
\text { EXCEL analysis and Working Model Analysis } \\
\text { using protractor on computer screen. } \\
\text { Rebuild, Test and Analyze } \\
\text { (If time permits) } \\
\text { Introduction to relatively advanced } \\
\text { mathematical concepts ( partial derivatives, } \\
\text { gradient, linear approximation of nonlinear } \\
\text { equations) for analysis of fourbar mechanisms. }\end{array}$ & $\begin{array}{l}\text { Write a report and develop a lesson plan for } \\
\text { high school mathematics class using the } \\
\text { concepts introduced for fourbar mechanism } \\
\text { design and analysis. } \\
\text { Vectors, Dot and Cross Product of Vectors } \\
\text { Latitude and Longitude, Introduction to GPS, } \\
\text { Using spherical and ellipsoidal earthmodel to } \\
\text { find distance between two points given their } \\
\text { latitude and longitude. }\end{array}$ \\
\hline DAY -5, July 2, 2004 & $\begin{array}{l}\text { Tour of Mechatronics Laboratory. } \\
\text {-Forward and Inverse Kinematics of Robots } \\
\text {-Multiple solutions and basic trigonometry } \\
\text { applications for inverse kinematics } \\
\text {-Righty and Lefty configuration } \\
\text {-Demonstration and Experiments with LEGO } \\
\text { Robots suitable for middle and high school. }\end{array}$ & $\begin{array}{l}\text { Complete Project/ Report/Lesson Plan if } \\
\text { necessary. } \\
\text { Discussion \& Question and Answer. } \\
\text { Wrap Up. }\end{array}$ \\
\hline
\end{tabular}

Grading Scheme : Classwork (50\%), Project Report and Lesson Plan (50\%) Optional Take Home Project (20\% - Bonus Points) 